\title{
List A Short Delay Free Recall
}

National Cancer Institute

\section{Source}

National Cancer Institute. List A Short Delay Free Recall. NCI Thesaurus. Code C120396.

The third part of the California Verbal Learning Test for Children. Following the List B test, the child is asked to recall words from List A, without an additional presentation of the List A words. 